\title{
Colonialidad como emparentamiento y limpieza de sangre: un breve estudio sobre los aportes de Santiago Castro-Gómez.
}

\section{Coloniality as a relationship and blood cleansing: a brief study on the contributions of Santiago Castro-Gómez.}

DOI: 10.32870/sincronia.axxv.n80.7b21

\author{
Celeste Florencia Ramirez \\ Universidad Nacional de San Martín (MÉXICO) \\ CE: ramirezcelestef@hotmail.com / ID ORCID: 0000-0001-9351-0154
}

Esta obra está bajo una Licencia Creative Commons Atribución-NoComercial 4.0 Internacional

Recibido: 31/03/2021

Revisado: 30/04/2021

Aprobado: $14 / 06 / 2021$

\section{RESUMEN}

En el presente trabajo, a la luz de la lectura del filósofo Santiago Castro-Gómez, intentaremos dilucidar su concepción acerca de la colonialidad del poder y la manera en que tal dispositivo codificó los cuerpos conforme al discurso de la limpieza de sangre. De manera que, en el primer apartado, desarrollaremos brevemente dos tipos diferentes de teorías sobre el poder: por un lado, la teoría de la colonialidad del poder, presentada por el sociólogo peruano Aníbal Quijano; por otro lado, la analítica del poder, desarrollada por Michel Foucault. Ambas teorías, que parecen inconmensurables, son puestas en diálogo por nuestro filósofo. En la segunda parte de nuestro trabajo, nos dispondremos a presentar las prácticas y el modus operandi correspondientes a la colonialidad del poder para manifestar su singularidad en comparación a otro tipo de poderes. Asimismo, desplegaremos de qué manera cierto sector de la población, en un intento por consolidar sus intereses familiares y personales, utilizó estas prácticas para limitar la corporalidad. En tercer lugar y a modo de conclusión, realizaremos un breve bosquejo acerca del vínculo entre la colonialidad del poder y las prácticas políticas de la actual Colombia. 
Palabras claves: Estudios Postcoloniales. Taxonomía de cuerpos. Teoría heterárquica del poder. Colonialidad. Castro-Gómez.

Palabras clave: Estudios Postcoloniales. Taxonomía de cuerpos. Teoría heterárquica del poder. Colonialidad. Castro-Gómez.

\section{ABSTRACT}

In the present work, in the light of the reading of the philosopher Santiago Castro-Gómez, we will try to elucidate his theory about the coloniality of power and the way in which such a device codified the bodies according to the discourse of blood cleansing. So, first, we will briefly develop two different types of theories about power: on the one hand, the theory of the coloniality of power, presented by the Peruvian sociologist Aníbal Quijano; on the other hand, the analytics of power, developed by Michel Foucault. Both theories, which seem incommensurable, are put into dialogue by our philosopher. In the second part of our work, we will prepare to present the practices and modus operandi corresponding to the coloniality of power to manifest its uniqueness in comparison to other types of powers. Likewise, we will show how a certain sector of the population, in an attempt to consolidate their family and personal interests, used these practices to limit corporality. Third, and by way of conclusion, we will make a brief sketch about the link between the coloniality of power and the political practices of current Colombia.

Keywords: Postcolonial studies. Hierarchic theory. Body taxonomy. Coloniality. CastroGómez.

\section{Introducción}

En principio, debemos comprender que uno de los propósitos de Santiago Castro-Gómez en su libro El tonto y los canallas (2019) es analizar el presente de Colombia, un presente fuertemente influenciado por las herencias coloniales (Castro-Gómez, 2019, p.60). Por este motivo, retrocede hasta los siglos XVII y XVIII para examinar lo que Aníbal Quijano denomino como colonialidad del poder. La colonialidad del poder consiste en un conjunto de técnicas y mecanismos para la dirección de la conducta que marcan el comportamiento y los modos de valoración de la sociedad hasta la actualidad colombiana. Castro-Gómez sostiene que la colonialidad del poder adviene como consecuencia de la consolidación del resguardo, i.e., de la confrontación de fuerzas entre el 
Imperio, la Iglesia, los encomenderos y los terratenientes criollos. Se trata del modo en que los criollos procuraron resguardar e incrementar su poder en el espacio social. Los criollos comenzaron a crear una red estratégica de parentescos a partir de sus intereses personales para asegurar la transmisión de los privilegios adquiridos y heredados. De esta manera, "se forman así grandes 'clanes familiares' que codifican los cuerpos conforme a su linaje y producen una "memoria" de los privilegios heredados" (Castro-Gómez, 2019, p.48). Aquí el filósofo colombiano quiere decir que el poder se mantenía dentro de ciertos grupos de familias mediante la creación de alianzas matrimoniales y estrategias de parentescos.

En este sentido, la colonialidad se constituye, tal como señalan Aníbal Quijano y Walter Mignolo, simultáneamente al proceso de conquista y la colonialización de las Américas (CastroGómez, 2019, p.45). De manera que esta técnica fue reproducida por colonos, terratenientes y encomenderos criollos de la Nueva Granada, quienes fueron perjudicados por el resguardo. Por lo tanto, si bien la colonialidad del poder se originó en las prácticas locales específicas de la Nueva Granada entre los siglos XVI y XVIII, el núcleo problemático radica en que, según la perspectiva de Castro-Gómez, Colombia aún se encuentra firmemente arraigada a vestigios coloniales.

\section{El concepto de "colonialidad" desde una perspectiva heterárquica del poder}

Como señalamos anteriormente, el énfasis principal de este capítulo es el vínculo que CastroGómez encuentra en dos tipos aparentemente diferentes de poder: la colonialidad del poder y la analítica del poder. Para realizar dicha investigación, nuestro filósofo intenta trazar una genealogía del primer tipo específico de poder. Sin embargo, él no utiliza el método macrosociológico propuesto por Aníbal Quijano, sino que aborda este concepto a partir del método genealógico de análisis formulado por Michel Foucault (Castro-Gómez, 2019, p.43).

Ahora bien, Castro Gómez afirma que la analítica desarrollada por Foucault hasta 1975 estuvo fuertemente influenciada por el pensamiento Nietzscheano, quien considera el poder como el entrecruzamiento de múltiples fuerzas con distintas intensidades, que disputan entre sí de forma tensionada. Para Nietzsche, cualquier fuerza se halla en relación con otras fuerzas, para obedecer o 
para mandar. El poder es justamente esta relación entre fuerzas dominantes y fuerzas dominadas. Las fuerzas dominantes o superiores se llaman activas; mientras que las fuerzas inferiores 0 dominadas, reactivas (cfr. Deleuze, 2015b, 59-64). Este modelo de la lucha permanente entre fuerzas de diferente índole es utilizado por Foucault para analizar las prácticas hospitalarias, escolares y carcelarias. Vemos entonces, y retomo a Castro-Gómez por la claridad de sus argumentos: "la analítica del poder consiste en levantar un diagrama de las fuerzas en conflicto, en trazar su genealogía, mostrando cuales son las diversas estrategias de lucha, las estratificaciones que se generan, la modificación histórica de las fuerzas que combaten" (2019, p.20). De manera que el poder no es el resultado de una jerarquía, sino que es el producto arbitrario y parcial de las fuerzas que lo componen. En suma, el poder puede entenderse como una red que une múltiples relaciones de poder que atraviesan, caracterizan y conforman la sociedad a nivel microfísico.

Sin embargo, a mediados de 1976, Foucault modifica este modelo microfísico del poder y opta por un análisis más global del poder centrado en la biopolítica. Tal tecnología aparece en la segunda parte del siglo XVIII y opera en la regulación de procesos globales que permiten a la población garantizar una vida productiva para el Estado. La biopolítica tiende a la búsqueda de cierto tipo de población, como ejes de normalidad, a través de la exclusión violenta y opresiva de aquellos que forman parte de la otredad. En palabras de Castro-Gómez: "la biopolítica declara como 'enemigos' de la sociedad a todos aquellos grupos que, por su origen étnico, lengua o religión no se ajusten a la norma poblacional deseada" (2019, p.21). La introducción de esta tecnología novedosa del poder permite al filósofo francés reflexionar acerca de los Estados totalitarios del siglo XX que surgieron en Europa: el fascismo, el estalinismo y nazismo. En efecto, en su curso Defender la sociedad (1975-1976), Foucault declara que la racionalidad biopolítica moderna conforma incluso el discurso de la "guerra de razas" fomentado por el nazismo. Recordemos que el principio rector de la eugenesia nazi era la "higiene racial", centrada no solo en las características genéticas y biológicas, sino también en las cualidades mentales y espirituales. Así, la eugenesia se convirtió en el eje central de la práctica médica con la intención de efectuar una transformación biosocial a través del control de la reproducción. El partido nazi quería eliminar todo tipo de discapacidades de la 
sociedad alemana, ya sea porque no fueran "aptos" para la sociedad (retrasados mentales, enfermedades congénitas, homosexuales, disidentes políticos), ya sea porque, aunque genéticamente saludables, no eran considerados alemanes (judíos, gitanos y eslavos). Así, se hizo una división ideológica entre aquellos que eran y aquellos que no eran considerados racial y genéticamente deseables (Geyer y Fitzpatrick, 2009, p.87).

En esta búsqueda genealógica, el filósofo francés intenta descubrir el origen de este tipo de discurso, a saber: creador de poblaciones oponibles constantemente en guerra. Foucault encuentra una fuerte conexión entre racismo y colonialismo, puesto que es concretamente en la colonización dónde opera el discurso de la superioridad física, étnica y moral como dispositivo biopolítico.

Ahora bien, como señalamos en la introducción, Castro-Gómez retoma el término colonialidad del poder de Aníbal Quijano; ésta, es una estructura específica de dominación desarrollada en las colonias americanas a partir de 1492. Esta categoría implicaba no solo el sometimiento y la dominación por la fuerza a mano armada, sino también el establecimiento de un vínculo de poder fundado en la idea de una superioridad étnica y cognitiva de los colonizadores sobre los colonizados. Los colonizadores impulsaban la idea de la existencia de "razas" que dividían por taxonomías a la población mundial, estableciendo una codificación sobre los cuerpos. En este sentido, existían "por naturaleza" sujetos superiores y otros inferiores, según la raza o población a la que pertenezcan. De manera que cada sujeto tenía asignado un lugar fijo e inamovible al interior de la jerarquía social. De hecho, es la noción de "raza" en la que hunde sus raíces epistémicas el colonialismo. Este tipo de clasificación jerárquica de la población permitió en el siglo XVI la consolidación del dominio español en América; en el siglo XVII encontró una justificación científica mayor con el modelo naturalista; y luego, en el siglo XIX, se fundamentó con el modelo biologicista.

A fin de cuentas, tanto Foucault como Quijano establecen un vínculo extrínseco entre racismo y colonialismo. Pero, Castro-Gómez explica que es imposible decir que Foucault estaba pensando en la colonialidad del poder tal como es definida por Quijano, puesto que el filósofo francés estaba interesado por el racismo ejercido al interior de las fronteras europeas. Sin embargo y en contraposición a Quijano, Foucault no se refiere al racismo colonial establecido en el siglo XVI 
como tampoco sostiene que el colonialismo posibilita todos los tipos de racismos, sino que se refiere a un tipo específico de colonialismo: el colonialismo inglés y francés surgido en el siglo XIX. Para Foucault, existen diferentes formas, algunas totalmente diferentes, de racialización, las cuales dependen de los agentes que intervienen, del contexto y de las diversas formas de poder.

Lo que le interesa principalmente a Castro-Gómez del giro foucaultiano hacia un modelo de análisis más global de poder es que Foucault postula, simultáneamente al nacimiento de la biopolítica, el origen de un sistema supraestatal de seguridad que permite, en el siglo XVII, el fortalecimiento de cada uno de los Estados. Más precisamente, en las lecciones Seguridad, territorio, población (1977-1978), Foucault plantea que las tecnologías de gobierno sobre la conducta humana utilizadas por el poder pastoral del medioevo pasaron a controlar las poblaciones en los Estados modernos europeos con la utilización de técnicas biopolíticas. Entonces, los Estados comienzan a controlar todo lo que pueda ser considerado perjudicial para la sociedad a través de una seguidilla de dispositivos internos de seguridad. Asimismo, también ejercen poder mediante dispositivos externos de seguridad para consolidad los vínculos tensos entre los Estados.

De este sistema supraestatal de seguridad surge la noción de "Europa". Foucault considera que dicho término se presenta recién en el siglo XVII causado por las relaciones coloniales de poder. La pluralidad de esta idea permite la conformación de un grupo de Estados que compiten entre sí, pero sin arriesgar la seguridad interna de cada uno de ellos ni del sistema en su totalidad (CastroGómez, 2019, p.27-28).

Ahora bien, este dispositivo supraestatal de seguridad, presentado por Foucault como sistema-interestatal, es lo que Quijano, al igual que Wallerstein, llamo como sistema-mundo. Hay que resaltar la pluralidad de este término, ya que Europa está constituida por una multiplicidad de Estados definidos pertenecientes a una red interestatal, la cual se conforma a partir de una equilibro de poder. Por eso, se trata de un "sistema", más que de un "imperio".

La pertinencia de este sistema-mundo es que luego Foucault profundiza su análisis hasta encontrar una nueva racionalidad gubernamental: la racionalidad mercantil. De manera que a partir del surgimiento de la liberalización del comercio se origina un nuevo dispositivo externo de 
seguridad que modifica radicalmente la noción de "colonialismo". El colonialismo ya no implica únicamente el dominio territorial de los países europeos sobre sus colonias, sino que agrega el dominio económico (Castro-Gómez, 2019, pp.30-31). Este nivel es denominado por Foucault como macrofísico.

En este punto podemos observar de qué manera Castro-Gómez va delineando el vínculo entre el filósofo francés y el sociólogo peruano. Si bien el análisis "heterárquico del poder" es propiamente foucaultiano y el concepto de "colonialidad del poder" es de Quijano, destacamos la lectura filosófica específica de Castro-Gómez: es aquí donde se encuentra la novedad.

Nuestro filósofo articula las diversas cadenas de poder, cada una de las cuales funciona con sus propias lógicas y se encuentran vinculadas a través de diferentes tecnologías presentes en la colonialidad. Esto no implica que no haya jerarquías de poder, de hecho, el nivel molar donde estas jerarquías circulan y el nivel molecular que rompe las estructuras vigentes (es decir, las jerarquías) se entrecruzan continuamente. "Constantemente se reconstituye el uno en el otro, o se extrae el uno del otro" (Deleuze, 2015a, p.272). Los poderes se encuentran en movimiento perpetuo, cambiando, penetrados por acontecimientos, singularidades o virtualidades que los hacen fluctuar. Los dispositivos se encuentran parcialmente conectados, porque se conectan, desconectan y desplazan de un punto a otro punto cualquiera. De manera que cuando Castro-Gómez retoma cinco jerarquías de clasificación social utilizadas a partir del siglo XVI: clase, raza, género, sexualidad y religión descriptas por Quijano, realiza una lectura foucaultiana de cada una de ellas: "esa producción de jerarquías no es en sí misma jerárquica, sino que obedece a una lógica heterárquica, es decir, a la articulación inductiva entre diferentes técnicas de poder" (Castro-Gómez, 2019, p.34). Si las teorías jerárquicas del poder plantean que los niveles más globales de poder estructuran y subordinan a los niveles menos globales, entonces la colonialidad del poder determina de manera jerárquica todas las relaciones de poder existentes. Sin embargo, "en una teoría heterárquica del poder no es posible hablar del capitalismo como si fuese portador de una sola racionalidad, sino como la conjugación entre diferentes tecnologías de gobierno" (Castro-Gómez, 2019, p.36). A partir de esta lectura, la colonialidad es entendida mediante múltiples dispositivos de gobierno que 
regulan y disciplinan a la población y operan tanto a nivel biopolítico como a nivel corpopolítico. Por este motivo, ya no diremos que hay una "colonialidad del poder, sino que hay muchos dispositivos coloniales" (Castro-Gómez, 2019, p.36).

\section{Colonialidad y limpieza de sangre: estrategias de emparentamiento}

Al comenzar su investigación, Castro-Gómez señala que el rasgo primordial de la colonialidad de poder es la dominación por medios no necesariamente represivos. Apunta, más específicamente, hacia la naturalización del imaginario cultural occidental para romper con otras visiones cognitivas, afectivas y volitivas del mundo.

De manera que "La colonialidad del poder hace referencia a la manera en que la dominación española procuró eliminar las 'muchas formas de conocer' propias de las poblaciones nativas y sustituirlas por otras que sirvieran a los propósitos civilizatorios del régimen colonial" (CastroGómez, 2005, p.63). De hecho, la cultura europea se transformó en una aspiración, puesto que era la manera de acceder al poder. Señala nuestro filosofo: "La colonialidad del poder se revela, entonces, como un deseo por identificarse con el conquistador europeo, esto es, de verse y definirse a sí mismos a partir del espejo del colonizador" (2019, p.48). En otras palabras, en la búsqueda de participar en el poder colonial, el deseo por ser parte de Europa atravesaba tanto a los colonizadores como a los colonizados.

Era necesario cumplir uno de los siguientes requisitos: tener "sangre de conquistadores" o tener "sangre noble". El primero implica validar tener descendencia directa de los pobladores españoles; el segundo, tener descendencia directa de un hidalgo. Castro-Gómez explicita:

De un lado la nobleza de privilegio, que se adquiría por ser descendiente de españoles aunque no fueran nobles-, de otro lado la nobleza de nacimiento, que se tenía desde la cuna por ser "hijo de algo", es decir, hidalgo. (2019, p.48).

Ahora bien, los grupos poblacionales de la Nueva Granada que no cumplían con uno de estos requisitos, eran considerados de menor calidad racial. Así, comenzaron a utilizar el término 
"blanco" para señalar a aquellos sujetos que lograron comprobar que eran descendientes directos de los primeros pobladores españoles o que tenían algún parentesco con una familia noble española.

En este sentido, el modelo platónico es claramente percibido: hay una idea superior como razón de serie y luego le siguen ideas vinculadas a la primera según sus graduaciones. El patrón u original que contiene toda la perfección es el hombre blanco y el resto de las ideas, los dominados, son como pinturas o imágenes, las cuales pueden discrepar de la perfección rápidamente, pero en modo alguno podrían contener más perfección de las cosas de cuales han sido tomadas. En suma, convertir al dominado en un hombre con la naturaleza, la subjetividad y las formas de relacionarse del hombre blanco europeo.

Castro-Gómez retoma los estatutos de limpieza de sangre constituidos en el Consejo de Toledo en 1449, mediante los cuales se prohibía el ingreso de judíos o árabes conversos al cristianismo a colegios mayores, órdenes militares y monasterios en la Península. Así, se intentaba marcar un distanciamiento entre los cristianos viejos y los judíos o árabes conversos. La única forma que tenían para acceder a dichas instituciones era realizar la llamada "prueba de sangre", un procedimiento a través del cual los candidatos debían certificar el árbol genealógico de la familia y ser sujetos a un extenso interrogatorio con el fin de acreditar que no llevan en las venas "sangre judía" o "sangre mora". Por lo tanto, la limpieza de sangre tiene un criterio esencial de diferenciación: la ascendencia genealógica. De hecho, el término "raza" comúnmente utilizado en la estructura del pensamiento de la limpieza de sangre no se relaciona con el color de piel, sino que significaba tener una mancha, un defecto, una ascendencia judía o musulmana.

Este tipo de estrategias fue apropiado por el grupo de criollos terratenientes del siglo XVII para crear una frontera étnica entre ellos y el resto de la población. De esta manera, podían mantener sus intereses familiares y personales. Castro-Gómez explica: "El punto clave es que los miembros de los clanes familiares empiezan a escenificarse ya no como "cristianos viejos", sino como "blancos" (2019, p.49). Los indios y mestizos eran llamados de manera despectiva como "castas de la tierra". Tal como en los estatutos de limpieza de sangre, la blancura no se trata de la 
tonalidad de la piel, sino de un conjunto de procesos de emparentamiento o de la búsqueda de descendencia europea.

En consecuencia, este tipo de poder no actuaba únicamente por la fuerza, sino que intentaba arrancar las formas de conocer el mundo que los dominados tenían para imponerles como de suyo la percepción y el lenguaje del dominador. En suma, la limpieza de sangre se establecía en el interior del imaginario de los dominados. Por eso, la represión se manifestó primordialmente en los distintos modos cognitivos de un ser humano: "los modos de conocer, de producir conocimiento, de producir perspectivas, imágenes y sistemas de imágenes, símbolos y modos de significación; sobre los recursos, patrones e instrumentos de expresión formalizada y objetivada, intelectual o visual" (Castro-Gómez, 2005, p.62). Así, los dominadores despojaron al dominado la legitimidad de las maneras de producir conocimiento y significaciones que estos últimos tenían. En efecto, cuando los mestizos incrementaban su capacidad económica, intentaban adueñarse de los signos distintivos de los criollos. Se casaban con mujeres blancas de familias empobrecidas, se aplicaban el don o doña, utilizaban ropaje y adornos propios de la nobleza, montaban caballos, llevaban armas, etc. Incluso, los caciques considerados sucesores legítimos de la nobleza indígena prehispánica exigían ser nombrados con títulos europeos tales como duque, marques o conde.

\section{Colonialidad y estrategias de emparentamiento: resguardo de los privilegios}

La colonialidad del poder surge por la confluencia de dos fuerzas que operan con lógicas enteramente distintas, a saber: el poder soberano y el poder pastoral. Ambas fuerzas se agencian y constituyen el resguardo. Por un lado, se encuentra el poder soberano que actúa por territorialización. A finales del siglo XV, España conforma un grupo de "capitanes de mediano rango, aventureros sin trabajo, campesinos sin tierra, soldados, marineros e hidalgos empobrecidos, que veían en los viajes de conquista la posibilidad de mejorar su situación económica y de encumbrarse socialmente" (Castro-Gómez, 2019, p.59). Este grupo, dirigido por la corona española, es enviado a explorar nuevos territorios para conquistar. El interés principal del soberano no es la población, sino 
la tutela de territorios y recursos metálicos. Dichos territorios debían ser organizados a partir de la juridización, la tributación, el vasallaje y la administración para asegurar la soberanía. Por otro lado, el poder pastoral se ejecuta por individualización. Este tipo de poder no buscar aumentar las riquezas del soberano, sino "la evangelización de los indígenas, la salvación de sus almas y la expansión del reinado espiritual de la iglesia por todas las naciones, conforme al mandamiento de Cristo" (Castro-Gómez, 2019, p.46). Foucault explica que la línea pastoral se refiere a prácticas egipcias, mesopotámicas y hebreas, mientras que la línea soberana deriva de prácticas griegas y romanas. Como podemos observar, son dos tipos totalmente diferentes de poder: "La máquina imperial opera sobre el territorio, mientras que la maquina eclesial opera sobre las subjetividades" (Castro-Gómez, 2019, p.46).

Ahora bien, el imperio y la iglesia notaron que la explotación de la mano de obra indígena y su exterminio podrían perjudicar sus intereses. Castro-Gómez comenta que, para los primeros, era considerado como una pérdida de soberanía; y, para los segundos, como una deslegitimación de su obra misionera. Por este motivo, ambos poderes aprueban las Leyes de Burgos en 1512 y las Leyes Nuevas en 1546. Estas encomiendas proponían organizar las comunidades indígenas separadas de los españoles, bajo la tutoría de un encomendero responsable de su evangelización. El resguardo atribuía las tierras a las comunidades indígenas (no en carácter de propietarios) y los tributos a la corona española. Asimismo, las comunidades indígenas eran separados de las demás castas, ya sea mulatos, mestizos, etc. Así, los colonos españoles y sus descendientes criollos fueron los más perjudicados por estos decretos, puesto que deseaban la posesión de las tierras y la mano de obra de los indios, pero ahora los indios tendrían un lugar en la economía de esa sociedad (cfr. CastroGómez, 2005, p. 261). Como nuestro filósofo explica, los intereses del poder soberano eran rotundamente distintos a los intereses de los encomenderos y terratenientes criollos, "ya que los resguardos evitaban legalmente que el fruto del trabajo indígena quedase enteramente en sus manos y bajo su jurisdicción" (Castro-Gómez, 2019, p.49).

Asimismo, a principios del siglo XVIII, el gobierno español cambia de los Austrias a los Borbones y estos últimos "se da cuenta de que la mano de obra mestiza se había convertido en el 
sector productivo más dinámico de las colonias americanas (Castro-Gómez, 2019, p.56). Por eso, declaran medidas para favorecer la limpieza de sangre de los mestizos, tales como el acceso a la educación superior, el ingreso al ejército o al sacerdocio, así como también la posibilidad de comprar y vender.

Pero, los criollos, al sentir que atentaban en contra de sus intereses, hicieron que las autoridades españolas reglamentaran de forma estricta las medidas jurídicas de blanqueamiento. Implementaron una taxonomía más precisa para medir la blancura de sangre que, asimismo, implementaba derechos y deberes según la casta a la que pertenecían. "Pertenecer a una 'raza' significaba tener una macula en el árbol genealógico familiar, llevar la mancha de la tierra por ser un individuo fruto del emparentamiento con negros, indios, mestizos, musulmanes, árabes, etc.". Podemos observar que el término "raza" era utilizado como sinónimo al de casta, por este motivo, los blancos no eran considerados como una raza.

De manera que las familias criollas aumentaron sus ingresos mediante la mano de obra indígena fuera del resguardo y el trabajo de los esclavos en la minería. Por este motivo, se volvió popular la frase "se obedece, pero no se cumple", ya que los criollos obtuvieron mayor independencia frente al poder de la corona española. Castro-Gómez ejemplifica dicha situación, la primera con Antón de Olalla, quien era un labrador y alférez de infantería de la Nueva Granada que participo de la expedición de Jiménez de Quesada en 1537. Sus descendientes comenzaron a realizar alianzas matrimoniales con el fin de mantener y aumentar el patrimonio heredado. De hecho, el segundo es el ejemplo del marido de la hija de Olalla, Francisco Maldonado de Mendoza, un hidalgo español que había llegado a Nueva Granada. Entre otras cuestiones, él fundo el Mayorazgo de la Dehesa de Bogotá, a través del cual se garantizaba que únicamente los miembros de su linaje podrían obtener sus bienes. De esta manera, obligaba a sus descendientes a utilizar su apellido. Así, se compuso un clan con las familias más prestigiosas, "clan que acaparó encomiendas, tierras, minas y además consiguió monopolizar el poder municipal y provincial en el Nuevo Reino de Granada" (Castro Gómez, 2005, p.69). 
Los criollos implementaron todo tipo de prácticas para escenificar su blancura socialmente como "El tipo de vestuario utilizado, el matrimonio católico, el uso distintivo del "Don", el tipo de oficio que desempeñan una persona, el lugar de la vivienda, el uso de emblemas heráldicos y la ostentación de títulos universitarios" (Castro-Gómez, 2019, p.50). Incluso la universidad era un centro de enseñanza en la que se vinculaba el poder pastoral con la colonialidad del poder. Estas instituciones eran regidas por la Iglesia y no por el Estado, quienes perpetuaban una Verdad rebelada y la misión evangelizadora en la sociedad. Así, la universidad "se dirigía hacia la cristianización de indígenas y otros grupos poblacionales en las Américas, algunas universidades establecieron cátedras de lenguas aborígenes con el fin de preparar a los misioneros para ejercer esta función moral y epistémica" (Castro-Gómez, 2019, p.51).

Las elites criollas tomaron a la educación universitaria como mecanismo para la exclusión de las castas. En efecto, uno de los requisitos para el ingreso a la academia era comprobar la limpieza de sangre, es decir:

[...] se exigía que tanto el cómo sus padres fueran hijos legítimos, que no desempeñaran oficios bajos y que no estuviera manchado con la sangre de la tierra, es decir, que su familia no estuviera emparentada con negros, indios o mestizos" (Castro-Gómez, 2019, p.51).

Castro-Gómez explica que el procedimiento utilizado era similar al llamado "informaciones", el cual se utilizaba en España durante el siglo XV para que moros y judíos no pudieran participar del poder. Las llamadas "informaciones" consistían en un extenso interrogatorio frente a una comisión y un notario que transcribían las declaraciones del aspirante y de sus testigos para validad la limpieza de sangre. En efecto, "la universidad opera como un mecanismo de legitimación del capital cultural heredado" (Castro-Gómez, 2019, p. 51). La universidad colonial constituye una frontera legítima entre los criollos y las castas, puesto que estructura y valida los sectores dominantes a partir de la naturalización e universalización de las diferencias entre las clases.

Sin embargo, estos mecanismos no lograron frenar el rápido proceso de mestizaje en la Nueva Granada, al punto tal que el resguardo comenzó a ser una institución obsoleta. Como 
consecuencia, los criollos crearon una estrategia como defensa al avance del mestizaje, a saber: "la taxonomización de poblaciones conforme a un discurso de las castas" (Castro-Gómez, 2019, p.53).

Como vimos anteriormente, la corona española había utilizado la clasificación de la población como mecanismo para la recaudación de los atributos, ya que tanto los blancos como los indios debían tributar, mientras que los mestizos eran exonerados. Ahora bien, en este caso, CastroGómez encuentra otro modo de operar de los discursos clasificatorios, puesto que tenían la intención de distinguir su lugar en la pirámide social a partir de su grado de limpieza de sangre. De la misma manera que los científicos hacían descripciones sobre la fauna y la flora, los criollos crearon una "representación fisiológica de la población", es decir, la descripción de los sujetos a partir del color de la piel, los ojos, la estatura, el tipo de cabello. Mientras más "blancura" tenía un individuo, más posibilidades tendrá de ser reconocido socialmente y de obtener cargos públicos o eclesiásticos. Castro-Gómez explica: “El fenotipo de los individuos (blanco, negro, indio, mestizo) determinó su posición en el espacio social y su capacidad de acceso a aquellos bienes culturales y políticos que podían ser traducidos en términos de distinción" (2005, p.69).

En suma, el segundo objetivo de las estrategias de emparentamiento de los criollos que nuestro filósofo presenta es la centralización del poder, a saber: las estrategias utilizadas para mantener los privilegios familiares. Estas estrategias de emparentamiento tenían la pretensión de evitar el usurpamiento o la expropiación del poder por parte de algún tipo de instancia centralizada -tal como la corona española- y generar una separación entre los criollos y el resto de la población neogranadina. A fin de cuentas, "la colonialidad del poder es un tipo de poder que se caracterizaba por eludir sistemáticamente las leyes españolas y sus instituciones más representativas" (CastroGómez, 2019, p.59). Si bien nunca intentaron derrocar la corona española, es cierto que procuraron eludir sus controles y acomodar sus mandatos a sus intereses personales. Evitaban que la corona les fiscalizase los privilegios que acumulaban, tales como títulos de nobleza, trabajo esclavo, tenencias de la tierra. En suma, la colonialidad del poder hace referencia tanto a la creación estratégica de alianzas familiares en base a la blancura de sangre, como a la protección de los privilegios heredados y adquiridos. 


\section{Conclusión}

El discurso de la limpieza de sangre generaba un deseo interno por la blancura que abarcaba la sociedad colonial y constituía la subjetividad de los actores sociales. Como decíamos anteriormente, el imaginario de la blancura poco estaba relacionado con el color de piel, "como con la escenificación personal de un imaginario cultural tejido por creencias religiosas, tipos de vestimenta, certificados de nobleza, modos de comportamiento y [...] por formas de producir y transmitir conocimiento" (Castro-Gómez, 2005, p. 64). En efecto, el imaginario de la blancura englobaba un sistema de signos mediante el cual imponían distinciones asociadas al status social, formas específicas de producir conocimiento, certificados de nobleza, valores, maneras de comportarse y disciplinas. Foucault explica que el poder nos somete a la producción de la verdad, dado que es necesaria para que el poder funcione. De hecho, "somos juzgados, condenados, clasificados, obligados a cumplir tareas, destinados a cierta manera de vivir o a cierta manera de morir, en función de discursos verdaderos que llevan consigo efectos específicos de poder" (2001, p.34).

Por este motivo, Castro-Gómez afirma que es el proceso de taxonomización de los cuerpos el causante de la racialización de los cuerpos y no la creencia de una naturaleza verdadera preexistente en los cuerpos. Ahora bien, otro de los aspectos fundamentales de la colonialidad del poder es aquello que Castro-Gómez Ilamo "la expulsión del Estado" (2019, p.59). Debido a que los primeros pobladores de las Américas fueron individuos en una mala situación económica y social; luego de la conquista, comenzaron a reclamar recompensas tales como títulos de nobleza, dinero y privilegios de la Corona. Así, acumularon grandes cantidades de privilegios otorgados por la Corona y también obtenidos fuera de la ley a partir de la explotación de la mano de obra esclava y la limpieza de sangre descontroladas al estar lejos de las autoridades reales. Castro-Gómez explica que "tanto los adelantados y capitanes como sus descendientes directos, los criollos, constituyeron un "grupo aparte" que buscó siempre defender sus privilegios locales en contra de la autoridad central" (2019, p.59). Procuraron ignorar y evitar todos los controles y mandatos reales. 
La relevancia de estos puntos es que, según nuestro filósofo, hoy en día ambas características invaden la actualidad de Colombia. La colonialidad del poder forma parte del habitus de la élite gobernante de Colombia, ya que busca constantemente tergiversar la ley a favor de sus intereses personales. Tal como los criollos, la elite gobernante intenta eludir las normas y acomodarlas a su favor. Nuestro filósofo sostiene que estos comportamientos surgieron con el dispositivo de la blancura; sin embargo, esto no ha quedado en el pasado, puesto que, luego de las guerras de independencia, estas prácticas políticas marcaron la manera en que los individuos se vinculan con lo "público". Entonces, este tipo de comportamiento parece estar enraizado con los vínculos sociales neogranadinos en el siglo XVI. En suma, una vez que el partido político haya ganado las elecciones, el estado deberá recompenzar a ciertas familias e instituciones a través de la otorgación de puestos de trabajo, privilegios, contratos, etc. El Estado, a partir del clientelismo, conforma vínculos de poder para garantizar el apoyo electoral.

\section{Referencias}

Castro-Gómez, S. (2005). La hybris del punto cero: ciencia, raza e ilustración en la Nueva Granada. Bogotá: Pontificia Universidad JAVERIANA.

Castro-Gómez, S. (2019). El tonto y los canallas. Bogotá: Pontificia Universidad JAVERIANA.

Deleuze, G. (2015a). Nietzsche y la filosofía. Barcelona: Anagrama.

Deleuze, G., Guattari, F., \& Karraceleta, U. (2015b). Mil Mesetas: Capitalismo y esquizofrenia. Valencia: Pre-Textos.

Foucault, M. (2001). Defender la sociedad. Curso en el Collège de France (1975-1976). México: Fondo de Cultura Económica.

Geyer, M., \& Fitzpatrick, S. (2009). Beyond totalitarianism: Stalinism and Nazism compared. Cambridge: Cambridge University Press. 